\title{
UtTERANCE Understanding, KNowledge, ANd Belief
}

\author{
LARS D ÄNZER \\ University of Duisburg-Essen
}

\begin{abstract}
What is it to understand another speaker's utterance? A natural view is that such understanding requires at least the acquisition of propositional knowledge of the utterance's meaning. This view is challenged by cases in which it correctly seems to a hearer $\mathrm{H}$ as though an utterance means such-and-such, but where $\mathrm{H}$ doesn't form the belief that it means such-and-such due to a misleading defeater. Such cases have been claimed to be examples of understanding without belief, and a fortiori of understanding without knowledge. The paper examines this argument in detail and defends a mixed verdict: While the argument succeeds in showing that there is a reading of attributions of utterance understanding on which the natural view is false, such attributions also have a different reading on which the natural view may well be true for all the argument shows. In making the case for the second half of this claim, the paper gives center stage to the close intuitive connection between utterance understanding and communicative success.
\end{abstract}

\section{Introduction}

When we talk to each other in everyday life, we pursue many goals. We want to share or acquire information, convince, impress, or get others to do something. But there is one thing we almost always aim at when we talk to someone, no matter which further goals we are pursuing: We want those we are addressing to understand what we are saying. But exactly what does this amount to? What is it for someone to understand an utterance?

There is something like a default view concerning the nature of utterance understanding, which is both natural and arguably taken for granted by many

Contact: Lars Dänzer<lars.daenzer@uni-due.de> 
theorists. ${ }^{1}$ This view, which I'll label (UK), says that understanding an utterance requires coming to know its meaning; that is, coming to know the meaning of an utterance is a necessary condition for understanding it. Not only does (UK) have an almost truistic flavor, there are also quite a few things that can be said in its favor (Longworth 2008: 52-54). Despite this, (UK) has been challenged with a number of different arguments. This paper focuses on one of these challenges, which has been presented most explicitly by David Hunter (1998) and Elizabeth Fricker (2003). ${ }^{2}$ The argument draws attention to a class of cases that allegedly constitute counterexamples to (UK). The cases are ones where it correctly seems to a subject as though a speaker is saying such-and-such - this being the result of the normal and automatic exercise of the subject's linguistic competence in response to the speaker's utterance-but where the subject doesn't form the belief that the speaker is saying such-and-such due to a misleading defeater. In such cases, the proponents of the argument claim, we intuitively judge that the relevant subject understands the utterance. Therefore, they conclude, utterance understanding doesn't require forming a belief as to the utterance's meaning; and since knowledge requires belief, utterance understanding doesn't require coming to know its meaning either. ${ }^{3}$ Since this line of argument is the main target of the present paper, I call it TAR for short. I call the examples on which it relies the target cases.

So far, the challenge posed to (UK) by TAR hasn't been carefully evaluated. ${ }^{4}$ The primary goal of this paper is to fill this gap. I will argue that the right verdict on TAR is a mixed one: TAR is successful to the extent that it shows that there is $a$ reading of attributions of utterance understanding on which (UK) is false; but there is also a different reading of such attributions, and TAR does nothing to show that (UK) is false when construed in accordance with this second reading. My defense of the second half of this claim draws crucially on an intuitive connection between utterance understanding and communicative success which has

1. See, e.g., Davidson (2001: 125, 141), Dummett (1978: 171; 1993: 60), Evans (1982: 311-312), Heck (1995: 82; 2001: 5-6), Peacocke (1976: 170-171), Schiffer (1987: 3-6; 2003: 99).

2. In Hunter's paper the argument occupies central stage; in Fricker's, it is presented only as one argument among others (2003: 331, 345). Pettit (2002: 542-547; 2005) can also be interpreted as endorsing the argument, but his case is not fully clear. The official target of Pettit's argument is the view that understanding a linguistic expression (qua type) requires a belief as to its meaning, not the view that understanding an utterance does. Nevertheless, some of his remarks strongly suggest that he would also be willing to endorse the argument as it applies to utterance understanding.

3. As this sketch indicates, the argument is structurally similar to familiar arguments against the views that seeing that $p$ entails knowing that $p$ and that remembering that $p$ entails knowing that p. See Turri (2010) and Bernecker (2007) for recent installments of these arguments with respect to seeing and remembering respectively.

4. The argument has been endorsed by Malmgren (2006: 214 Footnote 36) and Barber (2013: 967). The only critical discussion of which I am aware is in Longworth (2008). However, Longworth's discussion of TAR is brief and only tentative. I look at it in Section 4. 
often been noted in the literature on speech acts and linguistic communication.

The structure of the paper is as follows. In Section 2 (UK) is stated more carefully and clarified in a number of respects. Section 3 offers a reconstruction of TAR and explains the motivation of its proponents. Next, in Section 4, I look at two responses to TAR which have been suggested in the literature and argue that both are ultimately unsatisfactory. In Section 5 I present the case for what I take to be right response to TAR, and Section 6 replies to some objections. Section 7 concludes by noting the implications of my verdict on TAR for the debate about (UK).

\section{Clarifying the Target Thesis}

Above, (UK) was characterized as the view that a necessary condition for understanding an utterance is coming to know its meaning. To clarify the intended claim, more must be said about (i) the notion of understanding that is at issue and (ii) the notion of knowledge involved. I start with the former.

The notion of utterance understanding hides a number of complexities, and so pinning down the intended notion requires some care. First, we are concerned with the understanding of utterances qua datable events or acts, that is, utterance tokens (as opposed to utterance types). We are not concerned with what is often called dispositional understanding, that is, the kind of standing understanding one has of the expressions (qua types) of a language.

Secondly, we are concerned with utterance understanding as a matter of understanding the meaning of an utterance, as opposed to merely hearing and making out the sounds or words uttered by a speaker. More specifically, I follow Fricker (2003) in focusing on the notion of understanding the (intended) 5 illocutionary force and content of an utterance. ${ }^{6}$ This is clearly one thing we often get at when we talk about "understanding an utterance" and "understanding what a speaker said" in everyday contexts, and for the rest of this paper these locutions are to be disambiguated accordingly.

Third, the notion of understanding we are concerned with is a success notion,

5. The parenthetical qualification is required only if one thinks that the actual illocutionary force and content of an utterance may deviate from the intended force and content. There are influential accounts of illocutionary acts, e.g., the intentionalist (or Gricean) accounts of Schiffer (1972) and Bach and Harnish (1979), according to which such a deviation is impossible. The rest of the paper is framed on the assumption that some such account is correct, as this allows me to drop the qualification and thereby simply the exposition. The focus on intended force and content will become relevant when we turn to the connection between understanding and communicative success in Section 5.1.

6. We can ignore utterances involving more than one illocutionary act for the purpose of this paper. 
which needs to be distinguished from its success-neutral counterpart. To see the contrast, compare claims of the following forms:

(1) H understood S's utterance.

(2) H understood S's utterance to mean such-and-such.

(3) $\mathrm{H}$ understood $\mathrm{S}$ to be saying such-and-such.

The success notion of understanding is the one present in claims of form (1): Such claims entail that $\mathrm{H}$ understood S's utterance correctly, that $\mathrm{H}$ got the meaning of S's utterance right. In contrast, claims of form (2) and (3) involve the successneutral notion. Such claims do not imply that $\mathrm{H}$ understood the utterance correctly, as shown by the fact that they leave it open that $\mathrm{H}$ misunderstood $\mathrm{S}^{\prime}$ s utterance.7

It is worth noting that the target cases threaten not only (UK), which features the success-notion of understanding, but also a closely related view concerning success-neutral understanding, namely, the view that understanding an utterance to have a certain meaning requires coming to believe that it has that meaning. ${ }^{8}$ To keep the discussion from getting overly complex, however, I will bracket success-neutral understanding in this paper and focus only on the success notion. Suffice it to say that the response to TAR I advocate in Section 5 can be extended to cover the view that success-neutral understanding requires belief.

There is a final distinction relevant for our purposes. The verb "to understand" exhibits an ambiguity between an achievement sense and a state sense, which also shows up in the context of attributions of utterance understanding (Vendler 1967: 112-113; Longworth 2008: 50-51; 2010: 3-4). In the state-sense, to understand an utterance is to be in the state of understanding it. In the achievementsense, it is to achieve understanding of the utterance, that is, to come to be in the state of understanding it, possibly as a result of a particular kind of process or episode. To illustrate, assume I've just heard and understood someone's utterance. In this situation, I might say both "I understood what she just said" and "I understand what she just said". The salient interpretation of the first sentence corresponds to the achievement sense, that of the second to the state sense.

As I have characterized it, (UK) concerns achievement-understanding: It says that understanding an utterance requires coming to know its meaning (achieve-

7. While distinct, the success and the success-neutral notions of understanding are closely connected. That $\mathrm{H}$ understands $\mathrm{U}$ (success sense) entails that $\mathrm{H}$ understands $\mathrm{U}$ as having a particular meaning (success-neutral sense) and that $\mathrm{U}$ in fact has that meaning.

8. While Fricker (2003) is exclusively and unambiguously concerned with the view that understanding in the success sense implies knowledge, Hunter's (1998) target is somewhat broader. He aims to undermine the view that "states of understanding are states of belief or knowledge" (1998: 560). In fact, much of his discussion is directed at the view that understanding in the successneutral sense implies belief, and the cases he describes are presented as counterexamples to this view. However, it is clear from his discussion that he takes these cases to also undermine (UK). 
ment). But it's again worth noting that there's a close cousin of (UK) concerning state-understanding that is also threatened by the target cases, namely, the view that understanding an utterance $\mathrm{U}$ requires knowing the force and content of $\mathrm{U}$ (state). I focus on (UK) because the salient interpretation of attributions of utterance understanding normally involves the achievement sense, whereas evoking the state sense requires some extra stage setting. But once again nothing hinges on this way of setting the focus. 9

Let's turn to the notion of knowledge that figures in (UK). In light of what has been said, we might formulate (UK) as the claim that $\mathrm{x}$ understands the force and content of an utterance $\mathrm{U}$ only if $\mathrm{x}$ comes to know U's force and content. What bears stressing now is that the kind of knowledge at issue is propositional knowledge. Properly understood, knowing the force and content of an utterance amounts to knowing what force and content the utterance has, which in turn amounts to knowing that the utterance has such-and-such force and content. ${ }^{10}$ Making this explicit we can state (UK) thus:

(UK) $\mathrm{x}$ understands (the force and content of) utterance $\mathrm{U}$ with force $\mathrm{F}$ and content $\mathrm{C}$ only if $\mathrm{x}$ comes to know that $\mathrm{U}$ has force $\mathrm{F}$ and content $\mathrm{C}$.

For instance, understanding an utterance in which the speaker asserts that $\mathrm{p}$ requires coming to know that the speaker has asserted that $p$ in making the utterance; understanding an utterance in which the speaker asks whether q requires coming to know that the speaker has asked whether $q$ in making the utterance, etc.

A second point also deserves mention. Some authors have argued, convincingly I think, that the word "knowledge" has both a strong and weak sense (e.g., Goldman \& Olsson 2009: 19-21; Hawthorne 2004: 68-70). While propositional knowledge in either sense is factive, a particular positive epistemic status is implied only by the strong sense, which has traditionally been the focus in epistemology. In the weak sense, on the other hand, true belief suffices for knowledge. This raises the question whether (UK) is to be interpreted as involving the strong

9. Fricker doesn't note the distinction and her discussion shifts back and forth between the two senses. Hunter draws a distinction between "states of understanding" and "events of understanding", which appears to be closely related to the distinction I am drawing, and makes it clear that his concern is with the former. However, his discussion leaves no doubt that he takes his examples to count just as much against the view concerning achievement-understanding on which I am focusing.

10. One might be tempted, at first sight, to construe the above formulation differently, viz., as involving the notion of objectual knowledge, so that "knowing the force and content of utterance $\mathrm{U}$ " is to be understood on the model of "knowing the father and mother of Paul." But there are very good reasons to resist this temptation; see Sainsbury (2002: 181-184) and Longworth (2008: $65-70)$. 
or the weak notion of knowledge. While this issue matters elsewhere, ${ }^{11}$ it can be left open here. TAR threatens (UK) on either construal; so, no matter which version is adopted, TAR must be dealt with, and the arguments considered in this paper all apply equally to the strong and the weak reading of (UK).

Finally, it bears emphasis that (UK) only makes a claim about a necessary condition for utterance understanding, not about a sufficient one. ${ }^{12}$ The proponent of (UK) is free to hold that understanding an utterance amounts to coming to know its meaning in a particular way (to be specified by the view). Nothing I say in this paper is incompatible with such a view; I simply leave the matter open.

\section{The Target Argument}

Before giving an explicit reconstruction of TAR, it makes sense to briefly consider the motivation of the theorists who have pressed it against (UK). This helps both to appreciate the force of the argument and to put it in perspective.

\subsection{The View in the Background}

Drawing on ideas articulated by John McDowell (1980; 1981), the proponents of TAR stress similarities between the kind of mental episode a hearer undergoes when perceiving an utterance in his native language and states of sensory perception. In understanding an utterance, they say, we normally just hear the meaning in the speaker's words. Accordingly, understanding a language is assimilated to possession of a quasi-perceptual capacity. Fricker (2003), who has offered the most carefully developed account along these lines, describes the phenomenology of utterance understanding as follows:

The most immediate personal-level psychological effect of . . . [a subject's] auditing of ... [an] utterance is that she enjoys a representation of a distinctive kind special to language understanding: a conscious representation of the content and force of the utterance. She hears the utterance not merely as sound, but as the speech act that it is. . . It is a fact of

11. There are objections to (UK) which focus specifically on the issue of epistemic status. In particular, it has been argued that, in contrast to knowledge, utterance understanding is compatible with the kind of epistemic luck that is characteristic of Gettier cases (Longworth 2008: 56-57; cf. Pettit 2002). In contrast to TAR, this line of argument counts only against the version of (UK) involving the strong notion of knowledge.

12. Thus, (UK) isn't threatened by alleged counterexamples to this sufficiency claim. For instance, Fricker (2003: 332) claims that coming to know what someone said in an utterance based on a translation doesn't amount to understanding the utterance. 
phenomenology that we enjoy such understanding-experiences, quasiperceptions of meaning. (2003: 325)

On Fricker's view this phenomenology is essential to utterance understanding. More precisely, she holds:

(QP) $\quad x$ understands (the force and content of) utterance $\mathrm{U}$ if and only if $\mathrm{x}$ enjoys a correct and aptly produced quasi-perception of the force and content of U. ${ }^{13}$

A crucial point for understanding $(\mathrm{QP})$ and its relation to TAR is that quasiperceptions of meaning, like ordinary perceptual experiences, are supposed to be belief-independent states; they belong to what is now often called the class of seemings. In listening to an utterance, it can seem to one that the speaker asserts that $p$, and one can thereby quasi-perceive him asserting that $p$, without one forming the belief that he asserts that $\mathrm{p}$. This explains why proponents of $(\mathrm{QP})$ deny that utterance understanding requires belief as to the utterance's meaning.

It's worth noting that in putting forward their quasi-perceptual view of utterance understanding Hunter and Fricker are motivated by a specific theoretical interest. They are concerned with the epistemological question of how we normally come to know (in the strong sense), or acquire justification for our beliefs about, what a speaker is saying. States or episodes of utterance understanding are supposed to play a central role in a satisfactory answer to this question: Just as perceptual beliefs amount to knowledge in virtue of being based on corresponding perceptual experiences, so beliefs as to what a speaker says amount to knowledge in virtue of being based on one's understanding - that is, seemings or quasi-perceptions - of what is said. On this view, states of understanding are the basis of beliefs about what is said, not those beliefs themselves.

\subsection{Reconstruction of the Argument}

With this background in place, we can now offer an explicit reconstruction of TAR. The first premise of the argument states that if (UK) is true, then so is (UB):

(UB) $\mathrm{x}$ understands (the force and content of) utterance $\mathrm{U}$ with force $\mathrm{F}$ and content $\mathrm{C}$ only if $\mathrm{x}$ comes to believe that $\mathrm{U}$ has force $\mathrm{F}$ and content $\mathrm{C}$.

13. To say that the experience is "aptly produced" is to say that it is in part the result of an exercise of the subject's dispositional understanding of the sentence uttered. 
This premise is based on the fact that (UB) follows from (UK) given the almost universally accepted principle:

(KB) $\mathrm{x}$ knows that $\mathrm{p}$ only if $\mathrm{x}$ believes that $\mathrm{p}$.

The second premise of the argument states that (UB) is false. This is supposed to be shown by apparent counterexamples to (UB). Here is a particularly clear and vivid example of the relevant sort, which is inspired by a scenario offered by Hunter (1998): ${ }^{14}$

Jane and the radio waves: Jane is fully but mistakenly convinced that radio waves of a particular type $\mathrm{K}$ interfere with her brain in such a way that whenever she is exposed to such waves, this invariably causes her to have mistaken impressions as to what people are saying. She also believes that her brain is currently exposed to waves of type K. At this point, her roommate Paul, unaware of what is going on with Jane, opens the door and says, "I'll be gone for the weekend." In hearing him speak, it (correctly) seems to Jane as if Paul is asserting that he will be gone for the weekend. However, since she is convinced that her comprehension is currently malfunctioning and producing mistaken impressions as to what people are saying, she doesn't form the belief that Paul is asserting this.

Does Jane understand Paul's utterance when she hears him speak? According to the proponents of TAR, the intuitive (and correct) verdict is that she does. But ex hypothesi Jane doesn't form a belief as to what Paul has said, owing to her misleading defeater. Therefore, (UB) is false. ${ }^{15}$

Together, the two premises entail that (UK) is false. In addition, the proponents of TAR note that (QP) accounts for the intuitive verdict about cases like Jane and the radio waves: Since Jane enjoys a veridical, aptly produced seeming as of the utterance's meaning, she understands the utterance according to (QP). So, not only do the target examples apparently undermine (UB) and (UK), they also provide support for $(\mathrm{QP})$.

14. Hunter describes multiple cases varying in the kind of misleading defeater involved, but these differences don't matter here. Similar cases are described by Longworth (2008: 55) and Pettit (2002: 544-545; 2005: 71-72).

15. As these remarks indicate, I take the argument against (UB) to be an instance of what is now often called the method of cases (e.g., Pust 2014). There has been much discussion recently about the correct reconstruction of this method. As far as I can see, these debates are irrelevant for the purposes of this paper. However, I should note that, despite skeptical challenges to the contrary, I take it for granted here that our intuitive judgments concerning cases like Jane and the radio waves constitute prima facie evidence for or against philosophical claims such as (UB). 


\section{Two Unsatisfactory Responses}

What's the right reaction to this argument? In this section, I look at two responses which have been suggested by Guy Longworth (2008) in his brief discussion of the argument. Longworth takes the availability of these responses to reveal "two large gaps" (2008: 56) in the argument, which would have to be closed before the argument could be taken to undermine (UK). However, I will argue that neither of the two suggested responses is satisfactory. Thus, the upshot of the section will be that some other response to TAR is needed if the threat it poses to (UK) is to be eliminated.

\subsection{Denying (KB)}

One possible reaction to TAR suggested by Longworth is to reject $(\mathrm{KB})$ and with it TAR's first premise, the claim that (UB) is true if (UK) is. According to Longworth, "it is no more obvious that propositional knowledge requires belief than that apparently belief-independent states ... require propositional knowledge" (2008: 56), a point that he attributes to Timothy Williamson (2000: 38$) \cdot{ }^{16}$ Thus, in application to the case at hand, Longworth's claim is that the truth of $(\mathrm{KB})$ is no more obvious than the truth of (UK), so that giving up (KB) is just as much an option as giving up (UK) when faced with the choice of giving up one of them.

That it is indeed $(\mathrm{KB})$ that should be dropped could be further motivated by noting that some philosophers have offered independent reasons against (KB). Their case is based on examples that it is natural to describe as involving knowledge but not belief (e.g., Radford 1966; Myers-Schulz \& Schwitzgebel 2013; Murray, Sytsma, \& Livengood 2013). One case involves a student, Kate, who takes a history exam for which she has studied many hours. All goes well until she reaches the last question: What year did Queen Elizabeth die? She has reviewed the date many times, but now she can't recall it. As time is almost up, she loses confidence and tells herself that she'll simply have to guess, writing "1603" into the blank space-which is in fact the correct answer. In describing this case, it is natural to say that Kate knew that Queen Elizabeth died in 1603, but much less so to say that Kate believed that Queen Elizabeth died in 1603. So, we seem to have a case of knowledge without belief.

Whether such cases actually succeed in undermining (KB) is highly contested (e.g., Armstrong 1969; Rose \& Schaffer 2013; Buckwalter, Rose, \& Turri 2015).

16. In the relevant passage Williamson discusses alleged counterexample to the claim that seeing that $\mathrm{p}$ implies knowing that $\mathrm{p}$. The text makes it clear, however, that Williamson eventually endorses a different response to the alleged counterexamples: He sticks to (KB), but denies that the alleged counterexample are really cases of seeing-that. I consider this line of response in Section 4.2. 
Fortunately, we don't have to decide this issue here, since there are compelling reasons why giving up $(\mathrm{KB})$ does not constitute a satisfactory reaction to TAR, no matter where one stands on (KB) in general. One such reason will become clear only in section 5.1, but the other can be given right away.

The point is this: While rejection of (KB) blocks TAR as presented in the literature and reconstructed above, the move does not thereby fully eliminate the threat to (UK) created by the target cases. For-albeit this seems to have gone unnoticed so far-these cases threaten (UK) not only via providing apparent counterexamples to (UB), but also by providing apparent direct counterexample to (UK). To see this, return to Jane and the radio waves, but this time ask, does Jane comes to know that Paul is telling her he'll be gone for the weekend? The intuitive answer is clearly negative: Although it correctly seems to Jane that Paul tells her he'll be gone for the weekend, she does not come to know this. The target cases are simply not among the cases which it is tempting to describe as involving knowledge without belief, such as the case of the unconfident examinee described above. This is confirmed by noting that none of the alleged counterexamples to $(\mathrm{KB})$ in the literature are structurally similar to the target cases; none features a subject who does not take appearances at face value because of misleading defeaters. The reason is surely not that the critics of (KB) are not aware of such cases; rather, it's that they don't think they pose a threat to (KB).

The upshot is that the target cases can actually be employed in two arguments against (UK), not only one. One is TAR, which goes via rejection of (UB). The other is the argument by direct counterexample just sketched. And while rejecting (KB) would block the first argument, it doesn't help in any way with the second. In fact, the only promising way to block the second argument seems to lie in resisting the verdict that Jane understands. But note that if one can resist this verdict, one can also resist TAR's second premise; and if one can do that, then there's no longer any pressure to give up (KB), at least as far as defending (UK) from TAR is concerned.

\subsection{Unqualified Rejection of the Verdict about the Target Cases}

The moral is that a satisfactory response to TAR must target its second premisethe claim that (UB) is false-and thereby also the intuitive verdict that there is utterance understanding in cases like Jane and the radio waves. The most straightforward version of this involves rejecting the relevant intuitive verdict unqualifiedly - that is, as just flat-out false, as opposed to false on some reading while true on another. This is the second possible response to TAR suggested by Longworth (2008: 56).

However, this response must reckon with the fact that the verdict on which TAR relies exerts a strong intuitive pull. I certainly feel that pull and the same 
is true for most people who have commented on the argument in the literature (see Footnote 4). Accordingly, an unqualified rejection of the verdict as mistaken must at the very least be accompanied by a plausible explanation of why our intuitions go wrong in this case. But how might such an explanation go?

Longworth himself doesn't offer any detail on how he thinks the verdict might be resisted. He suggests, though, that the relevant line of argument might parallel arguments for the claim that "seeing in the absence of belief or knowledge does not amount to seeing that such-and-such" (2008: 56). It is thus natural to look at Williamson's (2000: 37-38) influential defense of the claim that seeingthat entails knowing-that against alleged counterexamples that are structurally similar to the target cases. The cases are ones in which it visually seems to a subject that $p$, but where the subject doesn't come to believe that $p$ due to misleading defeaters. Williamson challenges the claim that subjects in such cases really see that $p$ by invoking the distinction between propositional seeing and objectual seeing, and more specifically, the distinction between seeing that such-and-such and seeing a situation in which such-and-such (2000: 38). The verdict that the subjects in the relevant cases see that such-and-such, he suggests, results from conflating the two: While it is true that they see a situation in which such-and-such, it is not true that they see that such-and-such. The latter seems true only because we fail to distinguish it properly from the former.

We need not take a stance on the merits of this move for the case of seeingthat. It suffices to note that it cannot be transferred to the case of utterance understanding to help explain away the verdict on which TAR is based. True, a distinction can also be drawn between propositional understanding and objectual understanding, and more specifically between understanding that an utterance has such-and-such force and content and understanding the force and content of an utterance. But, no matter what one thinks about the relation between the two, invoking this distinction doesn't help in our case, because-in contrast to Williamson-our concern is with the objectual notion, not with the propositional: (UK) is stated as a thesis concerning the former, not the latter. In effect, adapting Williamson's strategy to the case of understanding would have us say that Jane understands the force and content of Paul's utterance, but fails to understand that Paul asserts he'll be gone. But to say this is to concede what the proponent of (UK) wants to resist. ${ }^{17}$

17. I think the application of Williamson's move to the case of understanding fails also for another reason, namely, that the difference between propositional and objectual utterance understanding is merely superficial: Plausibly, to understand the force and content of an utterance is to understand that the utterance has such-and-such force and content. Longworth (2008: 63-64) claims that propositional understanding is non-factive, which would imply that this equivalence cannot hold. But while I agree that attributions of understanding-that have a non-factive reading, I think Longworth is mistaken in suggesting that they have only such a reading. In fact, his claim - which is based on consideration of a single example-flies in the face of a consensus in the 
Is there some other way to discount the intuitive verdict on which TAR relies? None has been suggested in the literature, nor do I see any plausible candidates. Consider, for instance, the proposal that the relevant intuitive verdict tracks a non-literal interpretation of attributions of utterance understanding, and that the verdict is actually false when such attributions are interpreted strictly and literally. This doesn't seem very promising. Some plausible story would have to be given for why and how the alleged non-literality arises, and it's not at all obvious how such a story might go. Also, the proposal cannot lay claim on any strong intuitive basis. Even when we think carefully about the matter, it doesn't seem that the claim that Jane understands Paul's utterance is false when construed strictly and literally. Contrast this with clear cases of non-literality like "I've said this a million times!" or "He's my sunshine". Here, any competent speaker will agree after a little reflection that what is strictly and literally said by these sentences is false (in any ordinary context), although what the speaker conveys by using them non-literally may well be true. Not so with the claim that Jane understood. Also, consider:

(4) Jane understands Paul's utterance, although she doesn't come to believe (or know) that he said he'll be gone for the weekend.

According to the view under consideration, this should be inconsistent when taken strictly and literally. But it doesn't seem to be. ${ }^{18}$

Of course, these considerations are not decisive. It can't be ruled out that this or some other explanation can be pulled off after all. However, the prospects look dim. In any event, until such an explanation is forthcoming, we lack any basis for responding to TAR by rejecting the intuitive verdict on which it rests as flat-out false.

In sum, neither of the two possible replies to TAR suggested by Longworth looks promising: Giving up (KB) doesn't succeed in eliminating the threat to (UK) created by the target cases, and rejecting the verdict on which TAR relies as flat-out false lacks any clear basis. If (UK) is to be upheld, a different line of response is needed.

literature on non-linguistic understanding that a factive reading is available (e.g., Kvanvig 2003: 190-191; Baumberger, Beisbart, \& Brun 2017: 7).

18. Similar points could be made with respect to the proposal that the intuitive verdict tracks only a conversational implicature. In addition, note that (false) conversational implicatures are normally invoked to explain why we judge something false that is strictly and literally true. In the present case, however, it would have to be claimed that a (true) conversational implicatures explains why we judge something true that is strictly and literally false. This latter kind explanation has much less plausibility, and I am not aware that it has been proposed for other linguistic constructions. 


\section{The Right Response: Two Readings}

The right reaction to TAR, I suggest, involves what I'll call a qualified rejection of the intuitive verdict on which the argument relies. To have a short label, let us call sentences by means of which we attribute understanding of the force and content of an utterance $u$-sentences. ${ }^{19}$ The response grants:

(T1) There is an interpretation of $\mathrm{u}$-sentences on which the intuitive verdict on which TAR relies is true.

But it adds:

(T2) There is also an interpretation of $u$-sentences on which the intuitive verdict on which TAR relies is false.

If these claims are correct, then the right assessment of TAR is also a qualified one: TAR succeeds in showing that (UB) and (UK) are false on one interpretation, but does nothing to show that they are also false on a second available interpretation.

I have already given my reasons for granting $\left(\mathrm{T}_{1}\right)$ in 4.2 , so the goal of this section is to establish (T2). My case has two components. First, I offer an argument for ( $\left.\mathrm{T}_{2}\right)$ that builds on the connection between utterance understanding and communicative success (Section 5.1). Second, I argue that we also find support for (T2) in our intuitive judgments about cases (Section 5.2). After addressing possible objections in Section 6, the concluding section considers the implications of the proposed assessment of TAR, including the question whether it is satisfactory for proponents of (UK).

One caveat before we start. My response to TAR involves the claim that $\mathrm{u}$ sentences have different "interpretations" or "readings". But one may ask what that's supposed to mean. Is the thesis that u-sentences are semantically ambiguous? Or that they are semantically underdetermined and get modulated or sharpened differently in different contexts? ${ }^{20}$ While these are certainly legitimate questions, I won't make any attempt to answer them here, for two reasons. On the one hand, drawing out carefully what exactly the difference between the two hypotheses comes to, and evaluating their pros and cons, would require a

19. I take such sentences to include not only those of the form 'A understands the force and content of $\mathrm{U}$ ', but also ones of the form 'A understands $\mathrm{U}$ ', 'A understands what $S$ says' and 'A understands $S^{\prime}$.

20. For accounts of semantic underdetermination and processes of modulation see, e.g., Ludlow (2014), Rayo (2013), and Recanati (2004). 
lengthy discussion which is beyond the scope of this paper. ${ }^{21}$ More importantly, I think that the answer to these questions doesn't matter for the main purpose of this paper, since the response to TAR I am offering can be made both sufficiently clear and plausible without pinning down the source of the multiple readings exhibited by u-sentences.

\subsection{Utterance Understanding as the Mark of Communicative Success}

There is, I suggest, a simple and persuasive argument for (T2). In a nutshell, it goes like this: When we talk about utterance understanding in everyday life, we often do so in such a way that utterance understanding is considered as the mark of communicative success, in one familiar sense of this latter notion. But when we look at cases like Jane and the radio waves, it is evident that communication in such cases does not succeed in the relevant sense. Therefore, there's a common interpretation of u-sentences on which there's no understanding in these cases. The rest of this section elaborates this argument.

When we speak, we mostly do so in order to communicate with others: We speak with communicative intent. And when we speak with such intent, there's always a question to be asked, and one that often matters greatly to us: Did communication succeed? Now, as has often been pointed out, the notion of communicative success is in need of disambiguation. Assume you tell me that the supermarket closes at 1opm today because you want to provide me with this piece of information. If I understand perfectly well what you're saying but don't trust you on the matter, and thus don't form the belief that the supermarket closes at 1opm, one might judge that communication has been unsuccessful. Or assume you ask me to turn down the music, but although I understand perfectly well what you're asking me to do, I refuse. Again, one might want to say that communication has failed. In the sense evinced by these judgments, failure of communication consists in failure of the speaker to achieve what are sometimes called his perlocutionary goals (Searle 1969; Bach \& Harnish 1979), that is, the kinds of goals characteristically associated with J. L. Austin's (1980) perlocutionary acts. ${ }^{22}$ Accordingly, we may say that the above judgments invoke the perlocutionary sense or standard of communicative success.

But there is clearly also another, at least equally natural and familiar notion or standard of communicative success. In the above cases, for instance, it is natural to say that although communication was not successful in one sense, it

21. The distinction between ambiguity (including polysemy) and underdetermination may be easy to draw in some cases, but it is much harder to draw in others. The case of u-sentences arguably falls in the area where deciding on the right classification is difficult.

22. Other examples of such goals include consoling someone, impressing someone, intimidating someone, making someone laugh, etc. 
was successful in another, because I understood perfectly well what you were saying. Contrast this with a case in which the person you're trying to inform (in English) about the supermarket's opening hours is Gustav, who (unbeknownst to you) happens to be a monolingual speaker of German with no knowledge of English, who doesn't get a word of what you're saying. Although you fail to achieve your perlocutionary goal in either case, there's a clear sense in which communication succeeds in the first case, because I understand what you're saying, but in which it fails in the second, because Gustav doesn't understand.

Thus, there seems to be a perfectly good and familiar sense in which communicative success turns on whether one's utterance is understood. This intuitive connection between communicative success and understanding has been noted and drawn upon in the literature many times (e.g., Bach \& Harnish 1979: 1216; Buchanan 2010; Davis 2003: 86; Heck 1995; 2002; Martinich 1984: 19; Meggle 1997; Neale 2016; Pagin 2008; Rumfitt 2005). Given that our target is the notion of understanding the force and content of an utterance, the relevant connection can be specified more precisely as follows:

(COM) In an instance where a speaker $\mathrm{S}$ addresses a hearer $\mathrm{H}$ with communicative intent by performing an illocutionary act, communication succeeds with respect to the force and content of S's utterance if and only if $\mathrm{H}$ understands the force and content of the utterance. ${ }^{23}$

This principle, I claim, captures a familiar notion or standard of communicative success, which I will call the uptake notion or standard of such success. ${ }^{24}$ Unless

23. Remember that I'm restricting attention to utterances in which a single illocutionary act is performed. To accommodate more complex cases the principle would need some fine-tuning. Remember also that I'm concerned throughout with the intended force and content of an utterance: If actual and intended illocutionary force and content can come apart, it's clearly understanding of the latter that's crucial for communicative success. Finally, I should note that some of the authors cited talk about understanding of speaker's meaning: They say that communication succeeds iff the addressee understands what the speaker means. But this difference is negligible given the intimate connection between intended illocutionary force and content and speaker's meaning: When a speaker performs a single illocutionary act in uttering a sentence (no indirect illocutionary acts, no implicatures), the intended force and content of his utterance exhaust what the speaker means in uttering the sentence. Accordingly, in such cases understanding the intended force and content of an utterance and understanding what the speaker means plausibly come to the same thing.

24. The label is apt because (COM) arguably captures what is right about Austin's (1980) claim that "uptake", i.e., understanding of a speech act's illocutionary force and content, is necessary for the successful performance of illocutionary acts. To see the connection, note that at least some illocutionary acts-e.g., telling someone that $\mathrm{p}$ or warning someone that $\mathrm{p}$-appear to be such that intending to perform them entails intending to be understood (or, in light of the point made in the next paragraph, intending to perform them entails communicative intent). Accordingly, fully successful performance of these acts seems to require "uptake" on the part of intended audience. Cf. Rumfitt (2005: 432). 
I explicitly indicate otherwise, it is always this uptake notion that I'm invoking in what follows when I talk about communicative success. For better readability, I will also leave the qualification "with respect to force and content" mostly implicit and simply talk about communicative success.

$(\mathrm{COM})$ is not just intuitively plausible, it is also grounded in, and thus supported by, two other highly intuitive claims. Let's say that a goal (or set of goals) is constitutive of communicative intent iff having it is necessary and sufficient for speaking with communicative intent. The first claim then simply spells out one clear notion of communicative success: If $S$ addresses A with communicative intent, then (in one important sense) communication succeeds just in case $S$ achieves the goals that are constitutive of his communicative intent. The second claim concerns the nature of the goals that are constitutive of communicative intent. As we saw above, the perlocutionary goals we purse in speaking are very diverse: We aim to share information, make people do things, impress, etc. But what is common to all and only the cases in which someone addresses another with communicative intent? As has also been noted many times, the obvious candidate is the aim of bringing about understanding of one's utterance in an addressee (Bach \& Harnish 1978: 12-16; Davis 2003: 86; Meggle 1997; Rumfitt 2005; Searle 1969: 46-47; Strawson 1964). If you speak with the aim of having your utterance understood, there's a clear sense in which you speak with communicative intent, no matter what your further goals might be. ${ }^{25}$ Conversely, if you're not speaking with the goal of being understood by someone else, as, for example, when you're merely testing a microphone, there's an equally very clear sense in which you're not speaking with communicative intent. So aiming at having one's utterance understood appears to be the goal that's constitutive of speaking with communicative intent, and achievement of that goal thus constitutes communicative success - which is what (COM) says. ${ }^{26}$

I take it to be clear, then, that (COM) articulates a very plausible link between utterance understanding and communicative success. I am not claiming that this link governs all our ordinary talk about utterance understanding, but only that it governs a substantial part of it. In other words, my claim is only that there is one familiar sense of talk about utterance understanding on which (COM) is true.

With this in mind, let's return once more to the case of Jane and the radio waves. However, this time the question to be asked is, is the case one in which communication succeeds? It is intuitively clear, I submit, that the answer is negative. This is certainly also how Paul would see the matter. Put yourself into his shoes. Assume that you'll be gone for the weekend and that you need Jane to feed the

25. Of course, the goal of being understood is intimately connected to our perlocutionary goals in that we normally cannot hope to achieve the latter without achieving the former.

26. Note that since (COM) has its basis in the nature of communicative intentions, the principle is about communicative success relative to the speaker's goals. This is worth pointing out since evaluations of communicative success are arguably sensitive to contextually salient interests and goals related to communication, which may, but need not, coincide with those of the speaker. 
pet fish while you're away. She always does that when she's aware that you're gone, and you know that. So you briefly stop by her room on your way out to tell her you'll be gone. Later you're made aware of the effect your utterance actually had on Jane due to her delusional beliefs. What would you think? Clearly, you'd conclude that your communicative attempt had failed.

Importantly, note that this judgment of communicative failure doesn't (just) track the perlocutionary sense of communicative success as opposed to the uptake sense. To see this, consider a variant of the case in which Jane has delusional beliefs of a different kind: She lacks any crazy beliefs about radio waves, but is instead convinced that you're constantly lying to her. Again, assume you told Jane that you'll be gone on the weekend and are later made aware of her delusion and thereby of your utterance's effect on her. You would naturally judge that although communication has failed in one sense (perlocutionary standard), it has succeeded in another (uptake standard). Now, compare and contrast this with the original version of the case: In that case, the natural judgment clearly is that communication has failed even in the second (uptake) sense.

This verdict is also supported by reflection on what communicative success (in the uptake sense) requires. What is involved in the goals we have when we speak with communicative intent? And what must be achieved accordingly if we are to consider communication to have succeeded? If we restrict ourselves for the moment to the case of assertion, the following seems clear enough: When we assert something with communicative intent, we aim at putting our addressee $\mathrm{H}$ in a certain position with respect to the proposition we assert, a position which includes at the very least that $H$ should come to believe what we assert, if he believes we are speaking truly. ${ }^{27}$ In the case of Jane, this plausible minimal condition on communicative success isn't met: Even if Jane is fully convinced that Paul is speaking truly, she won't acquire the belief that Paul will be gone for the weekend based on his assertion.

To sum up, then, the argument for (T2) is this:

$\left(\mathrm{P}_{1}\right) \quad$ There is a reading of $\mathrm{u}$-sentences on which $(\mathrm{COM})$ is true.

(P2) There is no communicative success (uptake sense) in the target cases.

Therefore, there is a reading of $\mathrm{u}$-sentences on which there is no understanding in the target cases.

27. Compare Rumfitt (2005: 441-443) for an explicit statement of the corresponding claim about utterance understanding, viz., that if $\mathrm{x}$ understands an assertion and believes the assertion to be true, then $x$ comes to believe what is asserted. This claim about understanding provides the basis for a more direct argument for (T2), i.e., one which doesn't make a detour to considerations of communicative success. However, because of its directness, this argument risks being accused of begging the question against the proponents of $(\mathrm{QP})$. This is one reason why I argue via the connection with communicative success. But, of course, the claim about understanding and my claim about the requirements on communicative success in the main text are closely connected: Each entails the other in conjunction with (COM). 
Before moving on, it is worth looking at this argument from a slightly different angle. What it brings out is a conflict between the intuitive verdict on which TAR relies and (COM). Granted the apparently obvious fact that communication doesn't succeed in the target cases, one cannot unqualifiedly accept both that verdict and (COM). This means, for one thing, that everyone who considers the link between understanding and communicative success articulated by (COM) to be real and important, including the many theorists who have relied on it in their theorizing (see the references above), must take issue with the relevant intuitive verdict. For another, it brings out a second reason, alluded to in Section 4.1, why responding to TAR by simply giving up (KB) isn't satisfactory: By giving us no means to resist the verdict on which TAR relies, if only qualifiedly, the move would still leave us with the uncomfortable clash between that verdict and (COM).

\subsection{Support from Intuitive Judgments}

If the argument of the last section is correct, we should also be able to find support for (T2) in our intuitive judgments about the target cases. That is, it should be possible to elicit the intuitive verdict that there is no understanding in such cases by framing the background or context of the presentations of the cases in such a way that the relevant reading is triggered. The argument also suggests what framing should do the trick: We would expect the postulated reading to be triggered in contexts where the question of communicative success is salient, for in such contexts this reading would be most relevant to the question under discussion. So the argument predicts that the intuitive judgments supporting (T2) will be triggered by contexts of this kind; and this, I submit, is exactly what we find.

First, however, it is worth noting in what kind of context the intuitive verdict that there is understanding in the target cases is typically triggered. Both Hunter and Fricker introduce the target cases only after much stage setting in which they draw attention to the role of seemings in comprehension and in which they make it clear that their main interest lies with those seemings. If what I say about the multiple readings of $u$-sentences is correct, it is no surprise that we are inclined to judge that there is understanding in the target cases in this kind of context, for the relevant reading has been made salient. But to conclude that this verdict is the only possible one, or even the most natural, is too hasty.

So let's consider a different context. Remember the little background story sketched earlier: Paul needs Jane to feed the pet fish because he's away for the weekend, so he briefly stops by her room on his way out to tell her that he'll be gone. Imagine further that after he's left, he gets a call from Jane's mother who tells him what's going on with Jane: what Jane believes regarding the effects of 
radio waves on her brain, and that she's fully convinced that today the waves are on. In this situation, we can imagine the following conversation to take place:

Paul: "I told Jane that I'll be gone for the weekend. Are you saying she didn't understand what I said?!"

Mother: "Exactly. Although she must have had the right impression as to what you were saying, she didn't get what you said due to her delusional beliefs."

I think this conversation would be very natural in the envisaged situation. What's more, it certainly seems that the answer provided by Jane's mother is perfectly true and appropriate. ${ }^{28}$ Compare the following possible answer:

Mother: "No. She understood what you said, but she didn't come to believe that you said you'll be gone for the weekend."

In sharp contrast to the first, this answer is very odd and unnatural. It would be very hard to make sense of in the imagined situation and might well leave Paul utterly confused. The reason seems clear: In giving this second answer, the mother would fail to take up the intended and salient interpretation of Paul's question and switch to a different interpretation of understanding-talk.

Some readers may find their intuitions less clear on these matters than I make them out to be. On the multiple-readings view I advertise this is to some extent predicted: It's a familiar phenomenon that once we have fixed on a particular interpretation of an expression, this interpretation remains salient and interferes with otherwise natural interpretations. But even if some readers' intuitions here are less clear than mine, they might still find themselves happy to say, "Well, in one sense Jane doesn't understand; but in another sense she does." But, of course, this intuitive response is also very much grist for the mill of my proposal.

I conclude, then, that we find the intuitive judgments predicted by my argument from Section 5.1. This strengthens the case for (T2) in important ways: First, these judgments provide independent support for (T2). Second, the case for ( $\mathrm{T}_{2}$ ) based on these judgments and the argument for (T2) from Section 5.1 mutually support each other: The argument from Section 5.1 provides additional reason for accepting the judgment that there's no understanding in the target cases, while our inclination to judge in this way in turn supports the argument from Section 5.1 by showing that its predictions are borne out.

28. I take it that "getting what $x$ said" is just a colloquial variant of "understanding what $X$ said". But nothing hinges on this assumption: The verdict remains the same if the mother's reply is formulated explicitly in terms of "understanding". 


\section{Objections and Replies}

As noted earlier, TAR has been pressed by proponents of (QP), who claim that the target cases both undermine (UK) and support (QP). How might these theorists react to my response? For reasons given in the concluding section, some might find it fully acceptable. But others might not. They might insist that (QP) is true without qualification, while (UK) is false, period. Let's call a theorist who takes this line a stubborn proponent of (QP). In this section, I consider how a stubborn proponent of $(\mathrm{QP})$ might try to resist my arguments in favor of (T2) and offer some replies.

Objection 1: The alleged support for (T2) from intuitive verdicts (Section 5.2) can easily be explained away as the result of a conversational implicature. When we are tempted to judge that Jane doesn't understand the utterance, this is due to the fact that, in the relevant context, saying that Jane understands has the false conversational implicature that Jane came to know what Paul said. But strictly and literally, it is true to say that Jane understands. This can be seen from an observation made earlier (Section 4.2): The alleged entailment of the claim that Jane understands - namely, that Jane comes to know, or form a belief as to, what Paul said-is always cancellable. It always seems fine to say:

(4) Jane understands Paul's utterance, although she doesn't come to believe (or know) that he said he'll be gone for the weekend.

Response: This observation doesn't favor the conversational implicature account over the multiple-readings diagnosis. As has often been pointed out, cancellability is (at most) a necessary condition for the presence of a conversational implicature, not a sufficient one. ${ }^{29}$ Cancellability indicates that the relevant aspect of the total utterance content is pragmatically (as opposed to semantically) determined; it doesn't indicate that we are dealing with a conversational implicature as opposed to some other pragmatic phenomenon, such as disambiguation or modulation.

What's more, other considerations speak strongly against the envisaged implicature diagnosis and its suggestion that $(\mathrm{QP})$ captures the only literal reading of attributions of utterance understanding. Most importantly, there are many perfectly ordinary situations in which we are happy to attribute utterance understanding in the absence of quasi-perceptions of meaning. Here's one such case:

29. Cf. Grice (1989: 44) and Carston (1988: 158). While the standard view holds that cancellability is a necessary condition for the presence of a conversational implicature, this has been challenged by Weiner (2006). 
Ulrike learns English. Ulrike is a native speaker of German who has tried to learn English on her own. Interpreting English is not yet fully effortless and automatic for her. When she is confronted with an utterance of an English sentence, she has to go through a series of more or less conscious cognitive steps: trying to recall the meanings of the words, figuring out the structure of the sentence, and putting it all together to infer a contextually plausible interpretation. Yet, Ulrike is able to arrive at the correct interpretations of utterances of various English sentences in this way. On one occasion, she is addressed by a stranger with the question, "Excuse me, where's the next ATM?" By going through the steps described above, she is able to determine that the stranger is asking her politely where the next bank machine is. She points the stranger in the right direction.

Ex hypothesi Ulrike did not undergo any relevant seeming. But, surely, we would normally say that she understood the stranger's utterance. In fact, it seems perfectly fine to describe the case by saying:

Ulrike understands the utterance, although she doesn't enjoy any quasiperception of its meaning.

While the multiple-readings proposal has no difficulty accounting for these facts, they pose very serious problems for the stubborn proponent of $(\mathrm{QP})$. Thus, once we widen our focus to include further cases and cancellability data, the former emerges as much more plausible than the latter.

Objection 2: The argument from the understanding-communicative success link (Section 5.1) isn't convincing. Why couldn't one deny ( $\left.\mathrm{P}_{2}\right)$ of the argument, the claim that there's no communicative success in the target cases? In fact, the assertion that there's no such success seems to simply beg the question against proponents of (QP).

Response: $\left(\mathrm{P}_{2}\right)$ doesn't beg any questions, because it isn't based on acceptance of (UK) or (UB); it is supported on independent grounds. First, it captures the intuitive verdict about the case (or so I claim), and on this basis enjoys prima facie justification. Secondly, I've presented an independent argument for the claim: In cases of assertion, communicative success in the uptake sense requires that the addressee $\mathrm{H}$ be put in a certain position vis-à-vis the proposition asserted, such that if $\mathrm{H}$ were to believe that the speaker speaks truly, he would come to believe the proposition asserted. (Since putting one's audience in this position is obviously crucial for the transfer of testimonial knowledge or belief, let's call this the T-position with respect to the proposition asserted.) The point, then, is that this minimal condition on communicative success isn't met in the target cases. 
But couldn't the opponent resist this argument? Why, he may ask, should we think that putting the audience in the T-position is required for communicative success per se? Why not think, instead, that it is required only by a combination of communicative and other successes?

An answer to this question was implicit in what I said in Section 5.I, but it's worth being explicit. As noted, I take it that communicative success in the uptake sense is tied to the goals that are constitutive of speaking with communicative intent: Such success is secured just in case these goals are met. But in the case of assertion, these goals clearly include putting the audience in the T-position with respect to the proposition asserted. Not only is this clear from reflection on one's own goals in asserting something with communicative intent, it is also shown by the fact that we wouldn't count someone as speaking with communicative intent if they didn't have the relevant goal. In particular, we wouldn't count someone as asserting something with communicative intent if they merely aimed at producing correct and aptly produced quasi-perceptions of meaning, but not also at putting their audience in the T-position with respect to the asserted proposition. For instance, imagine that in Jane and the radio waves Paul was aiming merely at producing a correct quasi-perception of meaning in Jane, but didn't have any goals beyond that; in particular, assume he had no intention to put Jane in the Tposition with respect to the proposition he asserts. Maybe Paul is fully aware of Jane's condition and just wants to have his fun with her. It's clear, however, that this would not be a case of Paul speaking with communicative intent. To speak with communicative intent, Paul must think of the quasi-perception of meaning as a means to a further end; and this further end must include Jane's entering the T-position with respect to the proposition asserted.

It is clear, then, that communicative success in the case of assertion does require putting the audience in the T-position with respect to the asserted proposition; veridical and aptly produced quasi-perceptions of meaning aren't sufficient for communicative success. What's more, such quasi-perceptions are also not necessary for communicative success. This is brought out unambiguously by the case of Ulrike. It is obvious that one may be fully aware that Ulrike doesn't enjoy quasi-perceptions of meaning and yet speak to her with communicative intent; and it is equally obvious that when Ulrike figures out what one is saying, communicative success in the uptake sense is thereby achieved. This observation strengthens the case for denying that there's communicative success in the target cases in an indirect way. A theorist who rejects $\left(\mathrm{P}_{2}\right)$ must provide some account of what constitutes communicative success on which to base his claim. For the stubborn proponent of $(\mathrm{QP})$, the obvious proposal would be that communicative success is constituted by veridical quasi-perceptions of meaning; in fact, if he accepts $\left(\mathrm{P}_{1}\right)$, he is committed to this account of communicative success. The 
Ulrike case shows that this conception of communicative success is mistaken and thereby adds to the case for $\left(\mathrm{P}_{2}\right)$.

Objection 3: Let's say that $\left(\mathrm{P}_{2}\right)$ is accepted. Still, why couldn't the proponent of $(\mathrm{QP})$ resist the conclusion of the argument by rejecting $\left(\mathrm{P}_{1}\right)$, the claim that there is a reading of $\mathrm{u}$-sentences on which (COM) holds true? For instance, why can't he say that communicative success requires not only understanding, but understanding plus belief, or understanding plus knowledge, where the understanding serves as the basis for the belief or knowledge?

Response: To start with, note that the Ulrike case shows that the stubborn proponent of $(\mathrm{QP})$ cannot say that understanding is a strictly necessary, although not sufficient, condition for communicative success. As just noted, the case shows that quasi-perceptions of meaning - and thus understanding as per $(\mathrm{QP})$ - aren't necessary for communicative success. Thus, if he grants $\mathrm{P}_{2}$, the stubborn proponent of $(\mathrm{QP})$ really is committed to denying any constitutive connection between understanding and communicative success. What he can allow regarding the relation between utterance understanding and communicative success is only the following:

(MEANS) On the only interpretation of $\mathrm{u}$-sentences there is, securing utterance understanding is often, but not always, the best (and only) means for securing communicative success (in the uptake sense).

The problem with this view is simply that it runs counter to the various considerations in support of $\left(\mathrm{PI}_{1}\right)$ that we have encountered. First, $(\mathrm{COM})$ certainly seems plausible, and (PI) offers a straightforward explanation of this fact: (COM) seems plausible because there is a reading on which it is true. The proponent of (MEANS), on the other hand, would have to come up with a story that attributes the prima facie plausibility of (COM) to some confusion. More importantly, we saw in Section 5.1 that (COM) is entailed by the apparent truisms that communicative success is achieved just in case the goals constitutive of communicative intent are achieved, and that the constitutive goal of communicative intent is having one's utterance understood. If there is a reading on which both these claims are true, as certainly seems to be the case, then (MEANS) is false. Finally, (P1) accounts for the fact that appropriate contexts elicit the intuition that there's no understanding in the target cases (Section 5.2), and also for the strong intuitive verdicts that there is both understanding and communicative success in the Ulrike-case. (MEANS), on the other hand, fails to account for either of these facts.

So, there's certainly much that speaks in favor of (P1) and against (MEANS). In fact, it's hard to see that (MEANS) has anything going for it other than that it is suggested by $(\mathrm{QP})$, that $(\mathrm{QP})$ has its attractions, and that it would be nice if there 
was a single correct account of utterance understanding (because $\mathrm{u}$-sentences don't allow for multiple readings). But that's clearly not an adequate basis for (MEANS) given the various reasons we have encountered for thinking that there is an interpretation of $\mathrm{u}$-sentences not captured by $(\mathrm{QP})$.

I conclude that the case for (T2) stands: On balance, the evidence clearly supports the view that there is indeed an interpretation of u-sentences on which there's no utterance understanding in the target cases. $(\mathrm{QP})$ captures at best one interpretation of such sentences, but it can't lay claim to capture the only interpretation these sentences allow.

\section{Conclusion}

The goal of this paper has been to assess the threat to (UK) posed by TAR. I have argued that the right verdict is a qualified one. While TAR shows that there is $a$ reading of $\mathrm{u}$-sentences on which (UB) and (UK) are false, there is also a different reading and TAR fails to establish that (UB) and (UK) are false when interpreted in accord with that reading. In other words, for all TAR shows, (UB) and (UK) might well be true on the second reading.

It is worth noting that this defense of (UB) and (UK) against TAR is modest in two respects. First, it shows only that there is a reading on which (UB) and (UK) may be true for all TAR shows, but not that $(U B)$ and $(U K)$ are actually true on the relevant reading. A more ambitious response would also include an argument for this stronger claim. I think that such an argument can be given, and that many of the elements required are already in place from what has been said here. However, giving and defending this argument is a task for a different occasion.

Secondly, the response-even if strengthened in the way just indicated-is modest in acknowledging that (UB) and (UK) are at best instances of what Lewis (1975) calls equivocal or unsharp analyticity, that is, sentences that are analytically true on one reading or sharpening but not on another. Is this too weak a defense of (UB) and (UK)? I don't see any reason to think so. I'm not aware that any proponent of (UK) has ever explicitly claimed more for this view than that, nor do I see any reasons why they should want to. Consider, for instance, a theorist who puts forward (UK) as part of an account of linguistic communication: $\mathrm{He}$ might identify the role of utterance understanding in such an account by means of $(\mathrm{COM})$ and endorse (UK) on this basis. ${ }^{30}$ Acknowledging that utterance un-

30. For instance, he might hold that what constitutes understanding and communicative success is recognition of the speaker's intentions (or recognition of what the speaker means) and that recognition of intentions entails coming to know these intentions. Something like this reasoning arguably underwrites endorsement of (UK) among authors in the Gricean tradition, such as Schiffer (1987) and Meggle (1997). 
derstanding talk also allows for a different interpretation, one on which (COM) and (UK) don't hold, need not bother this theorist in any way.

Something similar can also be said for the proponents of (QP). As far as I can see, my response to TAR doesn't conflict with anything that is of real importance to them. It is compatible with the claim that $(\mathrm{QP})$ is just as much an instance of equivocal or unsharp analyticity as (UK), and it also doesn't contradict the claim that quasi-perceptions of meaning play a central role in the right epistemological story of how we typically come to know, or have justified beliefs about, what others say. It's hard to see why the proponent of $(\mathrm{QP})$ should want to claim more than that.

It is clear, then, that the response to TAR I have defended has conciliatory potential. If it is correct, both the proponents of (UK) and of $(\mathrm{QP})$ might be able to get all they really care about and their disagreement might well be revealed as merely verbal.

\section{Acknowledgments}

I'm indebted to Brendan Balcerak-Jackson, Wolfgang Barz, Anna-Maria Asunta Eder, Miguel Hoeltje, Insa Lawler, Christian Nimtz, Raphael van Riel, Thorsten Sander, Peter Schulte, Thomas Spitzley, and two anonymous referees of this journal for helpful comments on earlier versions of this paper.

\section{References}

Armstrong, David M. (1969). Does Knowledge Entail Belief? Proceedings of the Aristotelian Society, 70, 21-36. https://doi.org/10.1093/aristotelian/70.1.21

Austin, John L. (1980). How to Do Things with Words (2nd ed.). Oxford University Press.

Bach, Kent and Robert M. Harnish (1979). Linguistic Communication and Speech Acts. MIT Press.

Barber, Alex (2013). Understanding as Knowledge of Meaning. Philosophy Compass, 8(10), 964-977. https://doi.org/10.1111/phc3.12075

Baumberger, Christoph, Claus Beisbart, and Georg Brun (2017). What Is Understanding? An Overview of Recent Debates in Epistemology and Philosophy of Science. In Stephen R. Grimm, Christoph Baumberger and Sabine Ammon (Eds.), Explaining Understanding (1-34). Routledge.

Bernecker, Sven (2007). Remembering without Knowing. Australasian Journal of Philosophy, 85(1), 137-156. https://doi.org/10.1080/00048400601176460

Buchanan, Ray (2010). A Puzzle about Meaning and Communication. Noûs, 44(2), 340371. https://doi.org/10.1111/j.1468-0068.2010.00743.x

Buckwalter, Wesley, David Rose, and John Turri (2015). Belief through Thick and Thin. Noûs, 49(4), 748-775. https://doi.org/10.1111/nous.12048 
Carston, Robyn (1988). Implicature, Explicature, and Truth-Theoretic Semantics. In Ruth M. Kempson (Ed.), Mental Representations: The Interface between Language and Reality (155-181). Cambridge University Press.

Davidson, Donald (2001). Inquiries into Truth and Interpretation (2nd ed.). Oxford University Press. https://doi.org/10.1093/0199246297.001.0001

Davis, Wayne (2003). Meaning, Expression, and Thought. Cambridge University Press.

Dummett, Michael (1978). Truth and Other Enigmas. Duckworth.

Dummett, Michael (1993). Origins of Analytical Philosophy. Duckworth.

Evans, Gareth (1982). The Varieties of Reference. Oxford University Press.

Fricker, Elisabeth (2003). Understanding and Knowledge of What Is Said. In Alex Barber (Ed.), Epistemology of Language (325-366). Oxford University Press.

Grice, Herbert P. (1989). Studies in the Way of Words. Harvard University Press.

Hawthorne, John (2004). Knowledge and Lotteries. Oxford University Press.

Heck, Richard G. (1995). The Sense of Communication. Mind, 104(413), 79-106. https:// doi.org/10.1093/mind/104.413.79

Heck, Richard G. (2002). Do Demonstratives Have Sense? Philosophers' Imprint, 2(2), 1-33.

Hunter, David (1998). Understanding and Belief. Philosophy and Phenomenological Research, 58(3), 559-580. https://doi.org/10.2307/2653756

Kvanvig, Jonathan (2003). The Value of Knowledge and the Pursuit of Understanding. Cambridge University Press. https://doi.org/10.1017/CBO9780511498909

Lewis, David K. (1975). Languages and Language. In Keith Gunderson (Ed.), Language, Mind and Knowledge (3-35). University of Minnesota Press.

Longworth, Guy (2008). Linguistic Understanding and Knowledge. Noûs, 42(1), 50-79. https://doi.org/10.1111/j.1468-0068.2007.00673.x

Longworth, Guy (2010). Some Models of Linguistic Understanding. The Baltic International Yearbook of Cognition, Logic and Communication, 5, 1-56.

Ludlow, Peter (2014). Living Words: Meaning Underdetermination and the Dynamic Lexicon. Oxford University Press. https://doi.org/10.1093/acprof:oso/9780198712053.001.0001

Malmgren, Anna-Sara (2006). Is There A Priori Knowledge by Testimony? The Philosophical Review, 115(2), 199-241. https://doi.org/10.1215/00318108-115-2-199

Martinich, Aloysius P. (1984). Communication and Reference. De Gruyter. https://doi. org/10.1515/9783110856255

McDowell, John (1980). Meaning, Communication and Knowledge. In Zak van Straaten (Ed.), Philosophical Subjects: Essays Presented to P. F. Strawson (117-139). Oxford University Press.

McDowell, John (1981). Anti-Realism and the Epistemology of Understanding. In Herman Parret and Jacques Bouveresse (Eds.), Meaning and Understanding (225-248). De Gruyter. https://doi.org/10.1515/9783110839715.225

Meggle, Georg (1997). Communicative Actions. In Ghita Holmström-Hintikka and Raimo Tuomela (Eds.), Contemporary Action Theory (Vol. 2, 251-272). Kluwer.

Murray, Dylan, Justin Sytsma, and Jonathan Livengood (2013). God Knows (but Does God Believe?). Philosophical Studies, 166(1), 83-107. https://doi.org/10.1007/s11098012-0022-5

Myers-Schulz, Blake and Eric Schwitzgebel (2013). Knowing That P without Believing That P. Noûs, 47(2), 371-384. https://doi.org/10.1111/nous.12022

Neale, Stephen (2016). Silent Reference. In Gary Ostertag (Ed.), Meaning and Other Things: Essays in Honor of Stephen Schiffer (229-342). Oxford University Press. https:// doi.org/10.1093/acprof:oso/9780199684939.003.0013 
Pagin, Peter (2008). What Is Communicative Success? Canadian Journal of Philosophy, 38(1), 85-116. https://doi.org/10.1353/cjp.0.0011

Peacocke, Christopher (1976). Truth Definitions and Actual Languages. In Gareth Evans and John McDowell (Eds.), Truth and Meaning (162-188). Clarendon Press.

Pettit, Dean (2002). Why Knowledge Is Unnecessary for Understanding Language. Mind, 111(443), 519-550. https://doi.org/10.1093/mind/111.443.519

Pettit, Dean (2005). Belief and Understanding: A Rejoinder to Gross. Mind, 114(453), 6774. https://doi.org/10.1093/mind/fzi067

Pust, Joel (2014). Intuition. The Stanford Encyclopedia of Philosophy (Fall 2014 Edition). Retrieved from http://plato.stanford.edu/archives/fall2014/entries/intuition/

Radford, Colin (1966). Knowledge - By Examples. Analysis, 27(1), 1-11.

Rayo, Agustín (2013). A Plea for Semantic Localism. Noûs, 47(4), 647-679. https://doi. org/10.1111/j.1468-0068.2011.00846.x

Recanati, Francois (2004). Literal Meaning. Cambridge University Press.

Rose, David and Jonathan Schaffer (2013). Knowledge Entails Dispositional Belief. Philosophical Studies, 166(Suppl. 1), 19-50. https://doi.org/10.1007/s11098-012-0052-z

Rumfitt, Ian (2005). Meaning and Understanding. In Frank Jackson and Michael Smith (Eds.), The Oxford Handbook of Contemporary Philosophy (427-453). Oxford University Press.

Sainsbury, Richard M. (2002). Knowing Meanings and Knowing Entities. In Sainsbury, Richard M. (Ed.), Departing from Frege: Essays in the Philosophy of Language (181-191). Routledge.

Schiffer, Stephen (1972). Meaning. Oxford University Press.

Schiffer, Stephen (1987). Remnants of Meaning. MIT Press.

Schiffer, Stephen (2003). The Things We Mean. Oxford University Press. https://doi. org/10.1093/0199257760.001.0001

Searle, John (1969). Speech Acts: An Essay in the Philosophy of Language. Cambridge University Press. https://doi.org/10.1017/CBO9781139173438

Strawson, Peter F. (1964). Intention and Convention in Speech Acts. The Philosophical Review, 73(4), 439-46o. https://doi.org/10.2307/2183301

Turri, John (2010). Does Perceiving Entail Knowing? Theoria, 76(3), 197-206. https://doi. org/10.1111/j.1755-2567.2010.01065.x

Vendler, Zeno (1967). Linguistics in Philosophy. Cornell University Press.

Weiner, Matthew (2006). Are All Conversational Implicatures Cancellable? Analysis, 66(2), 127-130. https://doi.org/10.1093/analys/66.2.127

Williamson, Timothy (2000). Knowledge and its Limits. Oxford University Press. 